\title{
Educação em tempos de pandemia da COVID-19: outras práticas educativas, mesmos
}

\section{dilemas}

\author{
Education in times of the COVID-19 pandemic: other educational practices, same dilemmas \\ La educación en tiempos de la pandémica del COVID-19: otras prácticas educativas, mismos \\ dilemas
}

Recebido: 20/10/2021 | Revisado: 27/10/2021 | Aceito: 20/11/2021 | Publicado: 28/11/2021

Cristina Aparecida Gonçalves dos Santos Silva

ORCID: https://orcid.org/0000-0002-5476-9822

Instituto Federal de Educação, Ciência e Tecnologia do Norte de Minas Gerais, Brasil

E-mail: criseula@otmail.com

Renilson Soares dos Santos

ORCID: https://orcid.org/0000-0003-3370-9000

Instituto Federal de Educação, Ciência e Tecnologia do Norte de Minas Gerais, Brasil

E-mail: renilsondossantos381@gmail.com

Camilo Miranda

ORCID: https://orcid.org/0000-0001-7230-9742

Instituto Federal de Educação, Ciência e Tecnologia do Norte de Minas Gerais, Brasil

E-mail: camilo.miranda@ifnmg.edu.br

\begin{abstract}
Resumo
Este artigo objetiva refletir sobre a educação em tempos de pandemia da COVID-19, abordando aspectos das práticas educativas mediadas pelas tecnologias, desigualdades no acesso aos recursos tecnológicos necessários ao estudo mediado, bem como a importância do trabalho para humanizar, na perspectiva da educação profissional e tecnológica, que tem o trabalho como princípio educativo. Para isso, numa abordagem qualitativa, foram realizadas pesquisas bibliográficas e observação não estruturada. Constatou-se que não houve preparação de professores, alunos e sociedade para o ensino mediado pelas tecnologias, impactando nas práticas educativas e com possibilidade de regressão da qualidade educacional. Não obstante, a educação profissional e tecnológica ofertada pelos Institutos Federais de Educação no Brasil (IF), poderá contribuir para produção de conhecimento necessário a reflexão sobre a sociedade atual e na proposição de novos caminhos, no cenário pós-pandemia.
\end{abstract}

Palavras-chave: Educação; Pandemia; Práticas educativas; Ensino.

\section{Abstract}

This article aims to reflect on education in times of COVID-19 pandemic, addressing aspects of educational practices mediated by technologies, inequalities in access to technological resources necessary for mediated study, as well as the importance of work to humanize, from the perspective of professional education and technological, which has work as an educational principle. For this, in a qualitative approach, bibliographic research and unstructured observation were carried out. It was found that there was no preparation of teachers, students and society for teaching mediated by technologies, impacting educational practices and with the possibility of regression of educational quality. Nevertheless, the professional and technological education offered by the FIs can contribute to the production of knowledge necessary to reflect on the current society and to propose new paths in the post-pandemic scenario.

Keywords: Education; Pandemic; Educational practices; Teaching.

\section{Resumen}

Este artículo tiene como objetivo reflexionar sobre la educación en tiempos de la pandemia de COVID-19, abordando aspectos de las prácticas educativas mediadas por tecnologías, las desigualdades en el acceso a los recursos tecnológicos necesarios para el estudio mediado, así como la importancia del trabajo para humanizar, desde la perspectiva del profesional. educativa y tecnológica, que tiene el trabajo como principio educativo. Para ello, en un enfoque cualitativo, se llevó a cabo la investigación bibliográfica y la observación no estructurada. Se encontró que no hubo preparación de docentes, estudiantes y sociedad para la enseñanza mediada por tecnologías, impactando las prácticas educativas y con posibilidad de regresión de la calidad educativa. Sin embargo, la formación profesional y tecnológica que ofrecen las IF puede contribuir a la producción de conocimientos necesarios para reflexionar sobre la sociedad actual y proponer nuevos caminos en el escenario pos pandémico.

Palabras clave: Educación; Pandemia; Prácticas educativas; Enseñanza. 


\section{Introdução}

O mundo foi surpreendido pela pandemia do novo Coronavírus, denominado pela Organização Mundial da Saúde de COVID-19, cujos impactos foram sentidos em todas as dimensões da vida, inclusive, na educação. Em outras palavras, de um momento para outro as pessoas precisaram adotar o isolamento social como forma de evitar alastramento da doença, até que se desenvolvesse uma vacina eficaz que pudesse reduzir a ação do vírus.

$\mathrm{Na}$ educação, o ensino presencial foi suspenso e sem que houvesse uma preparação adequada dos professores, alunos e familiares, deu-se início as aulas mediadas por tecnologias como a única forma de continuidade das atividades educacionais. Nesse contexto, é relevante considerar que, grande parte da população brasileira não possui acesso adequado aos recursos tecnológicos necessários ao acompanhamento das aulas virtuais ou apresenta algum tipo de desestruturação familiar que dificulta a concentração necessária ao aprendizado. Há também relatos sobre moradias pequenas, sem um espaço adequado ao estudo, elevado número de membros familiares convivendo num mesmo local entre outros. Soma-se a isso, a perda do nível de renda das famílias, que tiveram que ficar em casa, o que por si cria um nível de instabilidade que afeta a aprendizagem.

Nesse contexto, esta pesquisa objetiva refletir sobre a educação em tempos de pandemia da COVID-19, abordando aspectos das práticas educativas mediadas pela tecnologia, bem como das questões relacionadas a uma formação técnica na perspectiva crítica, não conformada com os interesses de preparação aligeirada de mão de obra para suprir as demandas do mercado capitalista de trabalho. Acredita-se que a partir da compreensão do contexto desencadeado pela Pandemia da COVID-19, pode-se fazer uma leitura do novo formato de ensino trazido pelas novas tecnologias. Interessa-nos as seguintes questões:

O ensino remoto tem contribuído para uma educação humanística? Os professores do ensino presencial receberam educação inicial e continuada que lhes permitissem realizar uma boa prática educativa mediada pelas tecnologias? Os alunos estão preparados para aprenderem a partir das aulas virtuais? As soluções tecnológicas ofertadas e adquiridas pelas instituições educacionais potencializam a mediação didático-pedagógica.

O presente artigo está organizado em três momentos: o primeiro empreende uma análise crítica acerca das tecnologias no contexto da mediação pedagógica. Já o segundo trata de alguns aspectos da preparação dos professores e suas práticas educativas em tempos de pandemia. O terceiro, por sua vez, aborda o que seria uma educação profissional e tecnológica para além da formação de mão obra aligeirada, para o mercado de trabalho. Por fim, explora-se o trabalho no sentido ontológico, como princípio educativo. Não se trata de um trabalho estático, pois está aberto a contribuições críticas e releituras da temática por outros pesquisadores e comunidade em geral.

\section{Metodologia}

Trata-se de uma pesquisa de natureza básica, pois como afirma Kauark (2010) possibilita a ampliação do conhecimento sobre o que já se sabe do assunto aqui pesquisado, com a intencionalidade de ampliar esse conhecimento. Enquadra-se como estudo Qualitativo, pois, "Não requer o uso de métodos e técnicas estatísticas. O ambiente natural é a fonte direta para coleta de dados e o pesquisador é o instrumento-chave.” (Kauark,2010, p.26). O estudo, a partir dessa abordagem qualitativa, valeu-se de dois tipos de pesquisas: a primeira foi a pesquisa bibliográfica, que segundo Duarte; Furtado (1991) utiliza técnicas de levantamento e seleção de material, bem como leitura e apontamento. Realizou-se ainda, a observação assistemática ou não estruturada, que segundo Lakatos; Marconi (2003), consiste em coletar e registrar fatos da realidade, sem que o pesquisador utilize meios especiais para isso, nem precise fazer perguntas diretas. Nesse sentindo, utilizou-se livros, artigos entre outros materiais pertinentes para a construção desse trabalho. Recorremos a autores como Peixoto e Carvalho (2011) Goeder e Arndt (2020) Lima (2003) Zabala (1998) Borges (2017) Ramos (2020) Ciavatta (2020), entre outros, para respaldo nessa pesquisa. 


\section{Resultados e Discussão}

\subsection{Tecnologias no contexto da mediação pedagógica: perspectiva crítica}

A tecnologia exerce sedução nas pessoas, que muitas vezes são levadas a adquirir e implantar recursos tecnológicos de forma acrítica. Nessa perspectiva e considerando o contexto educacional, um aspecto importante a ser avaliado é se há compatibilização desses aparatos tecnológicos à mediação pedagógica que se estabelece pela interação entre professores e alunos, com vistas a construção do conhecimento de acordo com Peixoto e Carvalho (2011).

É importante assinalar que embora haja diversas nomenclaturas para caracterizar tecnologias educacionais, optou-se pela terminologia Tecnologias Digitais de Informação e Comunicação (TDIC) que, é mais compatível com o momento atual em que se verifica a fusão de tecnologias de comunicação digital, computação e mídia online.

Em princípio cumpre esclarecer que a mediação pedagógica não é dependente fundamentalmente do uso da tecnologia, ainda que se reconheça que as TDICs favoreçam e potencializam a mediação didático-pedagógica. Assim, segundo Peixoto \& Carvalho (2011). Em uma perspectiva vigotskiana, pode se afirmar que o ponto fundamental na construção do conhecimento é a mediação exercida pelo professor, enquanto responsável por delinear e aplicar estratégias de ensino que instiguem o aluno, situando-o como protagonista do processo educacional.

Para Pinto, (2005) deve-se evitar o endeusamento da tecnologia educacional, não atribuindo a ela uma existência própria, dissociada da história humana. Afinal, os softwares e objetos de aprendizagem como Webquest, Pixton, Padlet e ainda os Games, entre outros, são decorrentes do aprimoramento da técnica humana ao longo do tempo e devem ser entendidos como meios através do quais o trabalho pedagógico do professor se realiza.

Dessa maneira, as TDICs devem ser instrumentos de facilitação da construção do conhecimento que, segundo Vigotski (1998), ocorre pela interação, primeiramente no nível externo, ou seja, junto às pessoas da comunidade e só depois é internalizado individualmente. Desse modo, Peixoto \& Carvalho (2011) advertem que os professores atuam na denominada zona de desenvolvimento proximal, organizando o aprendizado, dando-lhe sentido e tornando-o desejável para o aluno.

Em outros termos, a mediação didático-pedagógica é o trabalho do professor para que o aluno desenvolva seu potencial de aprendizagem, através da interação com outras pessoas e com a própria tecnologia que, enquanto constructo histórico cultural da humanidade deve estar a serviço dela. Nesse contexto, segundo os pesquisadores, Peixoto \& Carvalho (2011) o desafio é a utilização das tecnologias no sentido de facilitar o trabalho de mediação pedagógica do professor, na construção do conhecimento pelo aluno. Outro aspecto importante a considerar é a preparação dos docentes para lidarem com o suporte tecnológico na mediação pedagógica. Isso porque pesquisas indicam que os professores se sentem inseguros no manuseio da tecnologia, tendo dificuldades de promover inovações na prática pedagógica, é o que afirmam Oliveira \&; Moreira, (2015). A esse respeito, Oliveira; Moreira (2015) nos esclarece que não é a simples adoção da tecnologia educacional que vai elevar o padrão de formação dos discentes. Ao contrário, o aprimoramento do processo ensino aprendizagem, segundo os autores, só ocorrerá se os recursos tecnológicos forem efetivamente implementados como suporte à mediação pedagógica na construção do conhecimento, para além da simples transmissão de informações tal qual ocorria na pedagogia tradicional.

Dito de outra forma, a inovação educacional só será alcançada quando o professor empreender esforços conscientes na mudança pedagógica, alterando estratégias tradicionais, agindo como facilitador do processo ensino-aprendizagem, auxiliando os estudantes no uso crítico das tecnologias, para que acessem conteúdos que possam de fato potencializar a aprendizagem.

No mesmo contexto, não podemos deixar de assinalar como a pandemia da COVID-19 expôs as dificuldades quanto ao uso das ferramentas tecnológicas pelos agentes da educação.

(...) enquanto no ensino superior existe uma normativa que regulamenta a Educação a Distância, na educação básica essa era uma discussão ainda ausente ou bastante primária entre os educadores. Por conta disso, não é de se estranhar o 
quanto as práticas de ensino remoto causaram desconfortos e receios entre todos os envolvidos na comunidade escolar. (Goeder \& Arndt 2020, p.106)

Além disso, o evento pandêmico deixou evidente que as distorções socioeconômicas existentes no Brasil se refletem nas possibilidades desiguais de acesso aos recursos tecnológicos, bem como no uso das tecnologias de maneira autônoma.

Conclui-se que no processo de formação dos professores é preciso que se construa a compreensão de que o aprendizado vai depender da mediação, o que pode se dar com o apoio da tecnologia, de modo a propiciar interação dos sujeitos, bem como desenvolvimento no ambiente sociocultural do qual fazem parte. Não obstante, é importante asseverar que para que as TDICs consigam potencializar o processo ensino-aprendizagem elas precisam ser pensadas numa perspectiva estritamente pedagógica, considerando, inclusive a realidade dos alunos, sob pena de comprometimento da formação do conhecimento na perspectiva autônoma, em que o professor é facilitador do processo.

\subsection{Preparação dos Professores e Práticas Educativas em Tempos de Pandemia}

Apresentam-se, neste tópico, algumas reflexões sobre a forma como o ensino mediado por tecnologias foi introduzido na vida de professores e estudantes, sem uma preparação para essa mudança e os efeitos disso nas práticas educativas tradicionais.

Lima (2003), bem antes da pandemia do novo Coronavírus, já sinalizava quanto à necessidade de se investir na formação de professores o que possibilitaria uma capacitação de seus alunos para serem protagonistas, ativos, abertos ao conhecimento, conforme a demanda do novo contexto social. Essa autora criticava também a escassez de pesquisas e informações que possam levar a um diagnóstico do saber docente, com vistas a fomentar preparações adequadas a esse profissional que se deseja. "De fato, parece-me que antes de perguntar como fazer para que os professores ensinem melhor, é necessário perguntar como favorecer a aprendizagem docente (...).” (Lima, 2003, p.43)

$\mathrm{Na}$ visão de Lima (2003), as políticas educacionais brasileira, inspiradas em organismos internacionais como Banco Mundial, sempre enfatizaram a estrutura física das entidades educacionais, tecnologias, negligenciando a pedagogia e o professor. No entanto, no momento em que as avaliações internas e externas da educação evidenciam um quadro ruim, quase sempre a responsabilidade é atribuída ao professor e seu ensino. Por isso, é necessário enfatizar que:

(...) é preciso que as políticas públicas voltadas para a educação, visem melhores condições para o desempenho das atividades docentes. Devem fomentar, incentivar e destinar mais recursos para o processo de formação continuada dos professores da rede pública de ensino. Desse modo, é possível que muitos professores, além de terem acesso a diferentes recursos didáticos, estejam preparados e motivados para experimentá-los nas práticas educativas (Fonseca\& Barrére, 2013, p. 4).

Nesse cenário de pandemia da COVID-19, o aspecto da formação de professores, que já inspirava cuidados, ganha relevo. A decisão de programar aulas mediadas por tecnologias, a exemplo de quase todas as demais reformas educacionais que ocorreram em momentos anteriores, não foi objeto de discussão com a comunidade escolar, sobretudo professores. Em que pese o fato de que historicamente a escola "se baseia no falar-ditar do mestre" (Lévy, 1993, p.8), não se buscou diagnosticar o nível de capacitação dos professores para execução de aulas nesta nova modalidade e nem sobre as condições materiais para fazê-lo. Assim, sem uma capacitação específica para trabalhar na modalidade de ensino remoto, o professor apenas replicará, por meio da tecnologia disponível, sua experiência construída ao longo do tempo na sala de aula. (Tardif, 2007).

Também não se atentou para as condições socioeconômica dos alunos e suas famílias, se haveria possibilidade ou não de obtenção de recursos tecnológicos como: smatphones, lap-tops, acesso à internet, adequação de seus imóveis residenciais etc. Outro aspecto não considerado foi a estrutura familiar dos alunos, se eles teriam as condições psicológicas adequadas ao aprendizado em casa. 
Nota-se portando que estudantes e professores foram "empurrados" para a modalidade educacional mediada por tecnologias, sem que houvesse uma preparação para adaptação a esse novo modelo, gerando, em grande medida, uma falsa impressão de que o ensino-aprendizagem tem sido possível, nos níveis adequados, apesar da pandemia.

Não se pode negligenciar a preparação de qualquer profissional para o exercício de suas funções, sob pena de não se atingir os objetivos almejados. Imagine então no caso da profissão de professor que, segundo Zabala (1998) é bastante complexa, ensejando a necessidade de se conhecer e controlar as variáveis que intervém na sua atuação, numa perspectiva em que o fazer se daria a partir do conhecimento prático, porém com capacidade reflexiva, o que só é possível com a formação inicial e continuada adequadamente pensada e efetivada.

É bem verdade que não se esperava uma pandemia e, portanto é razoável que se considere a falta de um planejamento ou plano de contingência para o enfrentamento, especialmente no que diz respeito à educação. Todavia, diante dessa nova realidade, as medidas a serem tomadas poderiam e deveriam ter sido construídas ouvindo a comunidade escolar e a comunidade externa, no sentido de prospectar a melhor alternativa possível. Como bem nos ensina Zabala (1998), se temos dúvida sobre o que funciona na prática educativa temos por outro lado, uma série de referenciais teóricos que ao menos nos orientam sobre o que não funciona, evitando-se a repetição de velhos erros. Portanto, a construção da solução de aulas mediadas por tecnologias poderia ter sido previamente discutida com alunos, professores e sociedade, de modo a atenuar os efeitos ora vivenciados.

Com a participação coletiva, certamente constructos poderiam ter sido pensados de maneira a compatibilizar-se melhor em termos de sequências didáticas a serem realizadas, bem como uma melhor utilização do tempo e dos espaços virtuais na prática pedagógica. Uma aula mediada por tecnologias representa uma mudança drástica na prática educacional, já que o espaço e o tempo são totalmente alterados, em relação aquilo que se tinha na aula presencial: não se tem uma sala física de aula, podendo também não haver uma coincidência entre tempos e espaços virtuais em que os professores ensinam e os estudantes constroem a aprendizagem.

Um desafio adicional também é viabilizar a aprendizagem significativa cujo ensino do professor, na visão de Zabala (1998), precisa ajudar a estabelecer vínculos essenciais entre os novos conteúdos e os conhecimentos anteriores do aluno. Sobre isso temos que:

[...] para que o processo se desencadeie, não basta que os alunos se encontrem frente a conteúdos para aprender; é necessário que diante destes possam atualizar seus esquemas de conhecimento, compará-los com o que é novo, identificar semelhanças e diferenças e integrá-las em seus esquemas, comprovar que o resultado tem certa coerência etc. Ramos (2020) ainda apresenta uma análise relativa a um possível cenário educacional quando houver a liberação das aulas presenciais, mas ainda sem uma vacina que elimine definitivamente a ameaça do vírus. Imagina-se que será um grande desafio em termos financeiro e da própria prática educativa, já que os alunos precisarão manter certa distância, exigindo multiplicação de turmas e requerendo mais docentes, num cenário de extrema escassez financeira para tais investimentos. (Zabala 1998, p.37).

Conclui-se que professores, estudantes e comunidade em geral, não foram preparados para o novo contexto educacional em tempos de pandemia, em que as aulas presenciais, na sua totalidade, foram substituídas pelo ensino mediado por tecnologias. Isso tem gerado uma série de transtornos, podendo inclusive resultar em uma piora do nível educacional brasileiro, caso não se tome novas medidas de ajustes. Ciavatta (2020) pondera que não deveria haver imposição de Ensino à Distância (EaD), como medida para salvar o ano letivo, desconsiderando a falta de espaços adequados aos estudos em domicílios de diversos estudantes e sem a preparação de alunos e de professores, além de não se levar em conta o fato de que muitos país simplesmente não conseguem auxiliar os filhos nas tarefas educacionais, inviabilizando a aprendizagem.

Importante trazer para a discussão, por fim, que mesmo antes da COVID-19, não havia por parte do Governo (em sentido amplo) uma preocupação com a formação docente, visto que a Lei nº 13.415/2017 alterou consideravelmente a Lei de Diretrizes e 
Bases da Educação Nacional e promoveu uma série de mudanças no ensino médio, em especial curriculares e de carga-horária. Nesse sentido, a Lei Reformadora traz a possibilidade do credenciamento de profissionais sem a devida qualificação para trabalhar no EPT, tendo como premissa a falta de profissionais para atuar, especialmente, nas áreas técnicas. Cria-se, assim, a figura do docente com notório saber, que segundo Ramos (2017) fomenta a ampliação de certificações intermediárias e, também, promovem uma desvalorização do docente que atua na Educação Profissional e Técnica (EPT). Não há um foco na solução do problema, pelo contrário, há a proposição de uma solução paliativa, que inclusive, entra em conflito também com as Diretrizes Curriculares para a Formação de Professores, pois esses profissionais não possuem formação docente integral.

\subsection{Educação Profissional e Tecnológica: para além da formação de mão de obra para o mercado}

Silva e Queiroga (2019) explicam que as tecnologias mudaram a relação do homem com o trabalho. Na idade média, que vai do século V ao XV, o trabalho era artesanal. Com a revolução industrial, nos séculos VXIII e XIX, as máquinas passaram a executar muitas atividades humanas, tornando o trabalho bastante imbricado com os aparatos tecnológicos, necessitando cada vez mais da educação formal para prover conhecimento mínimo aos trabalhadores para operarem dispositivos tecnológicos utilizados no modo de produção capitalista.

Maria Luiza Belloni (2001), afirma que vivemos numa "sociedade do conhecimento", na qual a educação é a base para atender as necessidades do mercado de trabalho, que exige do indivíduo multicompetencias, multiqualificações. Nesse sentido, "A EaD é vista por muitos governos como um caminho mais barato, que atinge rapidamente um número maior de trabalhadores, e, ao mesmo tempo, como uma estratégia política [...]" (Martins ,1996, p. 4).

Dessa maneira, Oliveira (2012) nos adverte que apesar de não se saber de fato a data em que a EaD chegou ao Brasil, acredita-se que essa se inicia em meados do século XX, em função do iminente processo de industrialização, em que se necessitaria de políticas educacionais voltadas para a capacitação dos trabalhadores.

Ramos (2020) assevera que o processo educacional imerso no modo de produção capitalista busca uma educação mínima do trabalhador, suficiente para que ele exerça suas atividades, sem qualquer comprometimento com a estrutura de classes, em vigor. Portanto, não há compromisso do sistema educacional com uma educação crítica, emancipadora, que possa inclusive questionar o modelo de sociedade atual.

Essa autora nos ensina que a Educação Profissional e Tecnológica que se vislumbra, numa perspectiva crítica, é aquela em que o trabalho seja princípio educativo, propiciando uma formação geral, interligada com uma preparação técnica, integrando produção, cultura e ciência. Entende-se que há exemplo incipiente dessa proposta de educação integrada, nos Institutos Federais de Educação, Ciência e Tecnologia e que, conforme nos informa Ciavatta (2020) pode ser o germe para a construção de uma educação que abandone a histórica divisão entre formação básica e formação profissional, adotando uma perspectiva de currículo que conceba o homem integralmente, articulando trabalho, ciência, tecnologia e cultura, visando à formação emancipadora do ser humano para exercer com liberdade a atividade de sua vontade, e ainda contribuir para correções do rumo da sociedade.

Por isso, quando se observa o momento atual, em que educadores e educandos são compelidos a adotarem uma nova forma de ensinar- aprender, não há como não refletir se não seria a educação a distância, nesse momento, um caminho para um ensino "conteudista" visando a uma formação aligeirada para a preparação de mão de obra que atenda ao mercado capitalista de trabalho. E se levarmos em consideração a desvalorização em investimentos na carreira de professores, podemos entender a dificuldade de preparação desses trabalhadores para produzirem aulas nas suas próprias casas. Outro ponto a se pensar, seria a falta de recursos financeiros dos professores para adquirirem materiais e ferramentas para desenvolverem o trabalho, e do outro lado, os pais que não estão preparados, psicologicamente, intelectualmente e financeiramente para lidar com esse novo processo. 


\subsection{O Trabalho no processo de humanização}

Nesta seção busca-se apresentar o trabalho em seu sentido ontológico, a concepção do ensino profissional e tecnológico que tem o trabalho como princípio educativo e os desafios do ensino profissional e tecnológico no cenário de pandemia e póspandemia.

Borges (2017) aborda o aspecto da humanização em Marx, Engels e Lukács, mostrando-nos o pensamento desses autores sobre a importância do trabalho ou como o trabalho é fundamental para humanizar e é a partir da ação humana (trabalho) que se transforma o mundo em todas as suas dimensões. A conscientização, a maestria de se pensar, de formular a ação é o que o difere o ser humano dos outros animais.

Engels (1986) afirma que "o trabalho produz o homem e demostra essa afirmação de forma analítica, considerando a produção de Darwin” (Borges, 2017, p.103). Para Darwin, afirma a pesquisadora, o ser humano é diferenciado dos outros animais ao ter uma transformação na estrutura das mãos, a utilização consciente de gestos, a ação coletiva, exigência da linguagem, e como consequência o desenvolvimento humano.

Toda essa transformação é chamada por Lukács de "salto ontológico", Lukács (1978) define ontologia do ser social: "aquilo que define homem como ser, para além do mundo natural é o trabalho". (Lukács, 1978, p.103). Borges (2017) esclarece que o trabalho seria então próprio e preciso para o ser humano responder as suas necessidades tanto coletivas como individuais e é através do trabalho que se desenvolve a linguagem, a comunicação, desenvolvem instrumentos, ferramentas, procedimentos.

Os outros animais fazem suas produções inconscientes, por mais bela que seja. Mas é a conduta consciente que diferencia o trabalho como algo especificamente humano. Essa consciência é a capacidade que o ser humano tem de primeiro construir na sua cabeça a ideia e depois executá-la. Para Lukács, segundo Borges (2017), o que revela a constituição de um novo ser é a possibilidade de projetar em pensamento o que deverá realizar de intervenção no mundo real e criar inúmeras mediações para tal realização. Essa ação é chamada por Luckács de teleológica.

A formulação humana decorrente de sua atividade ontológica desenvolve assim ciência, tecnologia e arte. Para que o ser humano se torne humano, segue Borges (2017), é preciso que se aprenda. A educação humaniza na medida em que o ser humano se apropria daquilo que se produziam, eles se afastam dos animais, humanizar para a autora, é então afastar-se da determinação da natureza.

A consciência também é determinada pelo entorno histórico e social, em que o sujeito está inserido. O ser social é contraditório, é o movimento dialético, multideterminado, as formas de consciência determinam o mundo onde vivem.

Os seres humanos em suas individualidades são determinados por suas condições materiais de sua produção. O ser individual e a sociedade são múltiplas determinações de lado a lado. A educação traz em sua história, concepções de desenvolvimento fortemente marcado pelo pensamento positivista, revigorada no neo-positivismo e suas vertentes, remete a ideia de linearidade, e progresso com ideias de etnocentrismo e evolucionismo.

\section{Considerações Finais}

Sem a intenção de oferecer análise completa a respeito da temática, o presente estudo nos permite refletir que o ensino mediado pelas tecnologias, implementado abruptamente no contexto da pandemia da COVID-19, não tem cumprido o papel de ao menos manter os níveis educacionais verificados em momento anterior ao evento. Isso está relacionado, inclusive com a falta de preparação de professores, alunos e sociedade para lidarem com essa nova realidade educacional. Como bem pondera Ciavatta (2020), a imposição da $\mathrm{EaD}$ apenas com o intuito de passar a impressão de que o ano letivo de 2020 seria cumprido apesar da pandemia, sem os cuidados preparatórios já mencionados, tende apenas a mascarar a realidade, acarretando consequências negativas no nível de aprendizagem dos alunos. 
Não resta dúvida de que as tecnologias são importantes no cenário educacional atual. Todavia, o aparato tecnológico deve ser entendido como meio de complementar a prática educativa com a participação de professores, não tendo o poder de autonomamente realizar o processo ensino-aprendizagem. Em outras palavras, as tecnologias aplicadas à educação só terão valor se favorecerem e potencializarem a mediação didático-pedagógica.

Nessa perspectiva, tem-se que a educação profissional e tecnológica ofertada pelos Institutos Federais pode ser relevante para enfrentamento do momento atual, uma vez que produz, ainda que em estágio inicial, uma formação crítica, numa perspectiva curricular em que o homem é considerado em sua integralidade, havendo articulação entre trabalho, ciência, tecnologia e cultura. Dessa maneira, os egressos conseguirão empreender uma reflexão relativamente ao mundo e sobre medidas a serem adotadas para se obter uma outra sociedade pós pandemia, que seja mais humanizada. Para tanto, também é necessário o fortalecimento da Rede Federal de Educação Profissional, Científica e Tecnológica como promotora do entendimento da autonomia pedagógica, administrativas e financeira dos Institutos Federais, enquanto autarquias criadas pela Lei $\mathrm{n}^{\circ}$ 11.892, de 29 de Dezembro de 2008.

Recomenda-se uma reavaliação da modalidade educacional mediada pelas tecnologias, adotada nesse período de pandemia, com a participação de professores, estudantes e comunidade escolar pelo menos, no sentido de um realinhamento que possa compatibilizar as possibilidades tecnológicas com os objetivos educacionais, de modo a não comprometer a qualidade da educação ofertada com a realidade social dos envolvidos. Outro cuidado que se deve tomar é com a preparação de professores não capacitados para que consigam utilizar de maneira mais independente os recursos tecnológicos de modo a compatibilizá-los com a mediação didática-pedagógica que se pretenda, evitando difusão de ideias preconceituosas de que: (...) "somente as novas gerações seriam capazes de utilizar com destreza os artefatos tecnológicos, colocando em xeque a capacidade docente em criar condições de utilizar câmeras fotográficas, computadores etc." (Couto, 2013, p. 141).

Portanto, feitas essas considerações, não se pode olvidar o papel relevante da tecnologia no processo de ensino aprendizagem, enquanto ferramenta. De todo modo, entende-se que um grande entrave para a melhoria da qualidade da educação (em um sentido amplo) é a qualificação inicial e continuada docente, bem como da valorização e melhoria de suas condições de trabalho. Nesse sentido, as condições adversas ocasionadas pela pandemia do Covid-19 deixaram, mais uma vez, escancaradas essas necessidades.

\section{Referências}

Belloni, M. L. (2001) O que é mídia-educação. Campinas (SP): Autores Associados.

Borges, L. F. (2017). Educação, escola e humanização em Marx, Engels e Lukács. Revista Educação em Questão, Natal. 55(45), 101-26.

Ciavatta, M. (2020). *Aprendizagem operacional X preparo intelectual? Os desafios da EPT no Brasil.Canal do MEP-SINASEFE no You.Tube. https://www.youtube.com/watch?v=gyJMLrDjCg HYPERLINK

Couto, J. D. R. (2013). Mídias e Educação Infantil: desafios na prática pedagógica. Informática na Educação: teoria \& prática.

Duarte, S. V. \& Furtado, M. S. (1991) Manual para Elaboração de Monografias e Projetos de Pesquisa. UNIMONTES, 236P.

Fonseca, E. A. A.; \& Barrére, E. (2013). Possibilidades e Desafios na Utilização e Seleção de TDIC para o Ensino de Matemática em Escolas Públicas. ULBRA, Canoas, RS.

Goedert, L. et.al. (2020). Mediação pedagógica e educação mediada por tecnologias digitais em tempos de pandemia. Revista Criar Educação, Criciúma, 9, PPGE - UNESC

Lakatos, E. M., \& Marconi, M. A. (2003). Fundamentos de Metodologia Científica. Atlas.

Lévy, P. (1993). As tecnologias da inteligência: o futuro do pensamento na era da informática. Trad. Carlos I. da Costa. Editora 34

Lima, S. M. de. (2002). Aprender para ensinar, ensinar para aprender: um estudo do processo de aprendizagem profissional da docência de aluno-já-professores. UFSCar, 2003.Tese (doutorado)

Kauark, F. (2010) Metodologia da pesquisa: guia prático. Via Litterarum. 
Research, Society and Development, v. 10, n. 15, e370101522063, 2021

(CC BY 4.0) | ISSN 2525-3409 | DOI: http://dx.doi.org/10.33448/rsd-v10i15.22063

Kuenzer, A. (2020). O trabalho como princípio educativo. Canal do MEP-SINASEFE no You.Tube. https://www.youtube.com/watch?v=OoRPX-1BmIY.

Martins, L. A. R. (1996) Educação integrada do portador de deficiência mental: alguns pontos para reflexão. Integração, (26), 27-31.

Oliveira, R. M. da S. R. (2012). A tutoria no contexto EAD. UNIMONTES.

Oliveira, V. A. De \& Moreira, H. (2015). As tecnologias da informação e da comunicação como mediação pedagógica no curso de pedagogia. Revista IberoAmericana de Estudos em Educação, 10, 371-389, https://doi.org./10.21723/riaee.v10i2.778.

Peixoto, J., et.al. (2011). Mediação pedagógica midiatizada pelas tecnologias? Revista Teoria e Prática da Educação, 14, 31-38, https://doi.org/10.4025/tpe.v.14i1.15671.

Pinto, A. V. (2005) Conceito de Tecnologia. 2, Contraponto.

Ramos, M. N. (2020) Ensino Médio Integrado frente ao contexto de pandemia. *Canal do MEP-SINASEFE no You.Tube. https://www.youtube.com/watch?v=WV15n_5VDd8\&feature=youtu.be .

Silva, C. A.G. dos S. \& Joyce P. S. Q. (2019) O Papel do Tutor na EAD: Dificuldades e características nos dias Atuais. UNIMONTES- CEAD. Montes Claros MG.

Tardif, M. (2007) Saberes docentes e formação profissional. (8a ed.), Vozes.

Vigotski, 1., S. (1998) Pensamento e linguagem. (4a ed.), Martins Fontes.

Zabala. A. (1998) A prática educativa: como ensinar. Artmed. 